\title{
RETRACTED ARTICLE: Ammonium transport proteins from Archaeoglobus fulgidus
}

\author{
Daniel Cebo • Jörg R. Aschenbach • Martin Kolisek
}

Received: 24 January 2012 / Accepted: 26 July 2012 /Published online: 15 August 2012

(C) University of Navarra 2012, corrected publication 2022

The editors were made aware of partial overlap between already published material and the manuscript entitled "Ammonium transport proteins from Archaeoglobus fulgidus" by Daniel Cebo, Jörg R. Aschenbach and Martin Kolisek published online in the Journal of Physiology and Biochemistry. Contact with the authors was efficient, first author Daniel Cebo took full responsibility for any inconsistencies which had occurred and assured the editors that there were no bad intentions. All authors agreed that the manuscript should be retracted.

The editors were made aware of partial overlap between already published material and the manuscript entitled "Ammonium transport proteins from Archaeoglobus fulgidus" by Daniel Cebo, Jörg R. Aschenbach and Martin Kolisek published online in the Journal of Physiology and Biochemistry. Contact with the authors was efficient, first author Daniel Cebo took full responsibility for any inconsistencies which had occurred and assured the editors that there were no bad intentions. All authors agreed that the manuscript should be retracted.

D. Cebo $(\bowtie) \cdot J$. R. Aschenbach · M. Kolisek Institute of Veterinary Physiology,

Free University of Berlin,

Oertzenweg 19b,

14163 Berlin, Germany 